\title{
Molecular adjuvant interleukin-33 enhances the antifertility effect of Lagurus lagurus zona pellucida 3 DNA vaccine administered by the mucosal route
}

\author{
Y.X. Tu, X.P. Li, Z. Kadir and F.C. Zhang \\ Xinjiang Key Laboratory of Biological Resources and Genetic Engineering, College of Life Science and Technology, \\ Xinjiang University, Urumqi, China
}

\begin{abstract}
It has been shown that cytokines can act as molecular adjuvant to enhance the immune response induced by DNA vaccines, but it is unknown whether interleukin 33 (IL-33) can enhance the immunocontraceptive effect induced by DNA vaccines. In the present study, we explored the effects of murine IL-33 on infertility induced by Lagurus lagurus zona pellucida 3 (Lzp3) contraceptive DNA vaccine administered by the mucosal route. Plasmid pcD-Lzp3 and plasmid pcD-mIL-33 were encapsulated with chitosan to generate the nanoparticle chi-(pcD-Lzp3+pcD-mIL-33) as the DNA vaccine. Sixty female ICR mice, divided into 5 groups ( $n=12 /$ group), were intranasally immunized on days $0,14,28$, and 42 . After intranasal immunization, the antiLZP3-specific IgG in serum and IgA in vaginal secretions and feces were determined by ELISA. The results showed that chi(pcD-Lzp3+pcD-m/L-33) co-immunization induced the highest levels of serum IgG, secreted mucosal IgA, and $\mathrm{T}$ cell proliferation. Importantly, mice co-immunized with chi-(pcD-Lzp3+pcD-mIL-33) had the lowest birth rate and mean litter size, which correlated with high levels of antibodies. Ovaries from infertile female mice co-immunized with chi-(pcD- $L z p 3+p c D-m I L-$ 33) showed abnormal development of ovarian follicles, indicated by atretic follicles and loss of oocytes. Our results demonstrated that intranasal delivery of the molecular adjuvant $m I L-33$ with chi-pcD-Lzp3 significantly increased infertility by enhancing both systemic and mucosal immune responses. Therefore, chi-(pcD-Lzp3+pcD-mIL-33) co-immunization could be a strategy for controlling the population of wild animal pests.
\end{abstract}

Key words: DNA immunocontraceptive vaccine; Interleukin 33; Intranasal co-immunization; Antifertility effect; Anti-LZP3specific IgG; Lagurus lagurus

\section{Introduction}

Immunocontraception prevents pregnancy or oocyte fertilization by immunological mechanisms (1-3). The potential of immunocontraceptive vaccines to control the population of pest animals and wildlife such as foxes, mice, rabbits, African elephants, and white-tailed deer has been investigated (4-6). Mammalian zona pellucida glycoprotein (ZP) is made up of three sulfated glycoproteins (ZP1, ZP2, ZP3 or ZPA, ZPB, ZPC) that surround the oocyte (7). ZP3 glycoprotein, a primary sperm receptor, plays a critical role in specific sperm-oocyte combining and triggers the acrosome reaction $(8,9)$. It has been regarded as a promising target antigen for developing an immunocontraceptive vaccine because ZP3 antibodies (Abs) can block sperm-oocyte binding (9-11).
It has been shown that inoculation of murine cytomegalovirus-expressing mouse ZP3 (mZP3) (2) or purified mZP3 protein expressed by vaccinia virus (12) induces an anti-ZP3 immune response and results in a strong immunocontraceptive effect in immunized mice. Except for the direct effects of ZP3 Abs blocking the sperm binding site, some studies showed that ovarian pathological features characterized by depletion of primordial follicles and loss of follicles might cause the infertility induced by ZP3 protein vaccination $(7,13)$. Accumulated evidence indicates that both $\mathrm{T}$ cell and Ab-mediated reactions could cause ovarian pathology (14-16). For humans, a safe immunocontraceptive vaccine should not induce ovarian pathology. A number of research groups focused their

Correspondence: F.C. Zhang, Xinjiang Key Laboratory of Biological Resources and Genetic Engineering, College of Life Science and Technology, Xinjiang University, 14 Shengli Road, Urumqi 830046, Xinjiang, China. Fax: + 86-991-858-3517. E-mail: zfcxju@xju.edu.cn 
investigations on developing a safe and effective immunocontraceptive vaccine $(10,17,18)$. However, for wildlife pests such as Lagurus lagurus (a wild pest in the Xinjiang desert grassland, in Northwest China), immunocontraceptive efficiency should be the first issue of concern. Therefore, we tried to develop an effective DNA vaccine expressing LZP3 to decrease the fertility of $L$. lagurus. DNA vaccines can induce both cellular and humoral responses, but the level of immune response needs to be further improved, especially humoral responses.

The signaling of interleukin 33 (IL-33), a novel cytokine of the IL-1 family, and its receptor ST2 promotes generation of proinflammatory cytokines, chemokines, and Th2-associated cytokines in many cells of the immune system such as Th2 lymphocytes, basophils, eosinophils, mast cells, and natural killer cells $(19,20)$. IL33 has strong immunomodulatory functions and predominantly induces Th2 immune responses $(21,22)$ by activating dendritic cells (23). The Th2 immune response is important for induction of Ab production because Th2 cells effectively activate B cells to secrete Abs (24). Th2 immune responses to ZP3 antigens also play a role in autoimmune infertility caused by immunization with ZP3 proteins (12). Therefore, we chose IL-33 as a molecular adjuvant for our DNA vaccine.

Conventional vaccine delivery technologies are based on injection into the body of a mixture of protective components with an immunostimulatory agent (25). Direct injection of zona pellucida antigens into the body is not feasible for controlling the overpopulation of widely distributed pest animals (26). Mucosal vaccination has the advantage of needle-free administration, induces both systemic and mucosal immune responses, and can be used for mass vaccination (25). Our previous studies showed that nasal immunization induced both $\lg A$ and $\lg G$ $A b$ responses to mZP3 in mouse models $(27,28)$. In order to protect DNA from degradation, chitosan, a biodegradable cationic polysaccharide, was used to encapsulate the plasmid DNA as in our previous studies $(14,27)$.

In this study, LZP3 DNA vaccine (pcD-Lzp3) and a molecular adjuvant Mus musculus IL-33 (pcD-m/L-33) were encapsulated with chitosan and delivered intranasally into ICR mice, an outbred Swiss-derived model. The results showed that mice intranasally co-immunized with chitosan (chi)-(pcD-Lzp3+pcD-mIL-33) produced significantly higher levels of systemic and mucosal immune responses than mice immunized with chi-pcD-Lzp3 alone and decreased the birth rate, suggesting that IL-33 is a good candidate for developing an immunocontraceptive DNA vaccine for $L$. lagurus.

\section{Material and Methods}

\section{Animals}

Female ICR mice (6-8 weeks old) were purchased from the Center for Disease Control and Prevention
(Xinjiang, China). Animal experimental procedures were in compliance with regulations issued by the Science and Technology Department [approval number SCXK (Xin) 2003-0002] of Xinjiang Uygur Autonomous Region, China.

\section{LZP3 antigen and plasmids}

The core coding region of the $L$. lagurus ZP3 gene (Lzp3, GenBank No. AF515621) was cloned into pGEX$4 T-1$ to generate $p G E X-4 T-1-L z p 3$ plasmids, which were expressed in Escherichia coli BL21(DE3) as a GST-LZP3 fusion protein. GST-LZP3 was purified and quantified using a Bradford micro-assay kit (Tiangen, China), and was used as a specific antigen in ELISA or T-cell proliferation assays. Lzp3 was inserted into the eukaryotic expression plasmid pcDNA3.0 to produce a pcD-Lzp3 construct, which was used as the DNA vaccine. $\mathrm{m} / \mathrm{L}-33$ encoding the open reading frame of $M$. musculus $I L-33$ was inserted into the pcDNA3.0 plasmid to yield a pcDmIL-33 plasmid that was used as the molecular adjuvant. pcD-mIL-33 was prepared on a large scale and transfected into mouse hepatocytes by a hydrodynamic-based transfection method to detect the expression of mIL-33 (29). Briefly, $37.5 \mu \mathrm{g}(12.5 \mu \mathrm{g} / \mathrm{mL})$ plasmid was injected via the tail vein using a 21-gauge needle syringe. The plasmid solution injection was completed within 8-10 s and did not exceed $8-10 \%$ body weight according to the age and weight of mice. Total RNA was extracted from hepatocytes $8 \mathrm{~h}$ after injection, and the expression of the target gene was assayed by RT-PCR.

Preparation of chitosan-DNA complex nanoparticles Chitosan (170 kD, 85\% deacetylated) was purchased from Xindie Chitin Co., Ltd., China. Chitosan-DNA nanoparticles were prepared as described previously $(14,27)$. In brief, chitosan was dissolved completely in $1 \%$ acetic acid, then $0.14 \%$ chitosan solution $(\mathrm{w} / \mathrm{v})$ in 0.1 $\mathrm{M}$ sodium acetate buffer, $\mathrm{pH} 5.7$, and $100 \mu \mathrm{g} / \mathrm{mL}$ plasmid (pcD-Lzp3, pcD-mIL-33, or pcDNA3) solution in $0.2 \mathrm{M}$ sodium sulfate were incubated at $55^{\circ} \mathrm{C}$ for $30 \mathrm{~min}$ separately, then were mixed together quickly and shaken vigorously for $60 \mathrm{~s}$. The DNA plasmids were encapsulated with chitosan in a 1:7 ratio. The resulting nanoparticles were named chi-pcDNA3, chi-pcD-Lzp3, and chi-pcD$m / L-33$, respectively. Equal amounts of $p c D-L z p 3$ and pcD-mIL-33 were encapsulated together with chitosan to generate the nanoparticle chi-(pcD- Lzp3+pcD- $m / L-33)$. The mixture was kept at $4^{\circ} \mathrm{C}$ for $30 \mathrm{~min}$, then centrifuged at $10,000 \mathrm{~g}$ at $4^{\circ} \mathrm{C}$ for $20 \mathrm{~min}$. Pellets were resuspended in $0.9 \%$ sterile saline, and the final concentration of plasmid DNA in the chitosan-DNA complex was $2.5 \mu \mathrm{g} / \mu \mathrm{L}$.

\section{Examination of chitosan-DNA nanoparticles}

For scanning electron microscopy observation, $20 \mu \mathrm{L}$ chitosan-DNA nanoparticle solution was pipetted onto a 
glass slide and sprayed with silver powder after being dried for $30 \mathrm{~min}$. The surface of the chitosan-DNA nanoparticles was observed using scanning electron microscopy.

The protective effect of chitosan against nuclease degradation of DNA plasmids was checked by gel electrophoresis. The chitosan-coated plasmids and the corresponding naked plasmids $(3.4 \mu \mathrm{L})$ were separately digested with $0.3 \mu \mathrm{L} 5 \mathrm{U} / \mu \mathrm{L}$ DNase I (Takara, China) at $37^{\circ} \mathrm{C}$ for $30 \mathrm{~min}$ in a $20-\mu \mathrm{L}$ digestion system. Two microliters of $6 \times$ loading buffer was added to deactivate DNase I after each reaction. The protective effect of chitosan on DNA was detected by $0.7 \%$ agarose gel electrophoresis.

\section{Intranasal immunization with chitosan-DNA nanoparticles}

Sixty ICR female mice were randomly divided into 5 groups ( $n=12 /$ group). The five groups were randomly administered chi-(pcD-Lzp3+pcD-mIL-33), chi-pcD-Lzp3, chi-pcD-mIL-33, chi-pcDNA3, and chitosan. Inoculation was conducted intranasally on days $0,14,28$, and 42 by dropping $40 \mu \mathrm{L}$ of the chitosan-DNA nanoparticle solution (containing $100 \mu \mathrm{g}$ plasmid DNA) into a nasal cavity with a Gilson pipette. In the co-immunization group, each mouse was inoculated with a total of $80 \mu \mathrm{L}$ chi-(pcD-Lzp3+pcD$m / L-33$ ) nanoparticle solution (containing $100 \mu \mathrm{g}$ pcDLzp3 and $100 \mu \mathrm{g}$ pcD-m/L-33). In the blank control group, each mouse received $40 \mu \mathrm{L}$ chitosan solution.

\section{Sample collection}

Serum was collected from mice at 2, 4, 6, and 8 weeks after the first immunization and stored at $-20^{\circ} \mathrm{C}$ until ELISA detection for $\lg G$, and at the same time vaginal washings and fecal extracts were collected to measure secretory $\lg \mathrm{A}(\operatorname{sg} \mathrm{A})$. The vaginal washings were obtained by washing the mouse's vaginal cavity with $150 \mu \mathrm{L}$ sterile PBS containing $1 \%$ bovine serum albumin (BSA-PBS) nine times with a Gilson pipette. The vaginal washing was centrifuged at $10,000 \mathrm{~g}$ at $4^{\circ} \mathrm{C}$ for $20 \mathrm{~min}$. The supernatant was collected, $10 \mathrm{mM}$ protease inhibitor phenylmethylsulfonyl fluoride (PMSF) was added, and then it was stored at $-20^{\circ} \mathrm{C}$. The fecal sample was dissolved in $1 \mathrm{~mL}$ PBS at a final concentration of $0.1 \mathrm{~g} / \mathrm{mL}$ and kept at $4^{\circ} \mathrm{C}$ for $2 \mathrm{~h}$, and then vigorously shaken for $5 \mathrm{~min}$. The fecal sample was centrifuged at $10,000 \mathrm{~g}$ for $20 \mathrm{~min}$ at $4^{\circ} \mathrm{C}$, and the supernatant was collected and detected by ELISA.

\section{Assessment of specific IgG and slgA responses}

The levels of anti-LZP3 Abs in the serum samples, vaginal washings, and fecal extracts were determined using ELISA. A 96-well microtiter plate (Jet Biofil ${ }^{\mathbb{R}}$, China) was coated with $5 \mu \mathrm{g} / \mathrm{mL}$ recombinant LZP3 protein (in $10 \mathrm{~mL} 0.05 \mathrm{M}$ bicarbonate buffer, $\mathrm{pH} 9.6$ ) at $4^{\circ} \mathrm{C}$ overnight, and then was blocked with $3 \%$ BSA-PBST (PBS with $0.05 \%$ Tween 20) for $2 \mathrm{~h}$ at $37^{\circ} \mathrm{C}$. The serum and vaginal washings were diluted at $1: 100$ and $1: 4$ in $1 \%$ BSA-PBST, respectively. One hundred microliters of serum dilution, vaginal washing dilution, or supernatant of fecal extract was added to each well and incubated at $37^{\circ} \mathrm{C}$ for $1 \mathrm{~h}$. The plate was washed four times with $350 \mu \mathrm{L}$ PBST with a microplate washer. After washing, $100 \mu \mathrm{L}$ secondary, goat anti-mouse IgG conjugated with horseradish peroxidase (Southern Biotechnology Associates, USA) at a dilution of $1: 8000$ in 1\% BSAPBST was added to each well and incubated at $37^{\circ} \mathrm{C}$ for $1 \mathrm{~h}$. Other secondary $\mathrm{Ab} \operatorname{Ig} \mathrm{A}$ subtypes (Southern Biotechnology Associates) were diluted at 1:10,000. To

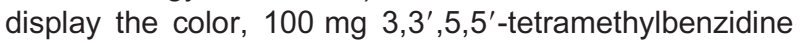
(TMB) (Shanghai Lanji Science and Technology Development Co., Ltd., China) was dissolved in $10 \mathrm{~mL}$ dimethyl sulfoxide (DMSO), then $100 \mu \mathrm{L}$ of the TMB solution and $42 \mu \mathrm{L} 0.75 \% \mathrm{H}_{2} \mathrm{O}_{2}$ were added to $10 \mathrm{~mL}$ $0.025 \mathrm{M}$ phosphate-citrate buffer, and $100 \mu \mathrm{L}$ of the resulting solution was added to each well. Finally, $50 \mu \mathrm{L} 2$ $\mathrm{M} \mathrm{H}_{2} \mathrm{SO}_{4}$ was added to each well to stop the reaction. The absorbance at $450 / 655 \mathrm{~nm}$ was read with a microplate spectrophotometer (Benchmark Plus ${ }^{\mathrm{TM}}$, Bio-Rad, USA). Antibody titers were determined by the ratio of the absorbance values (postimmune/preimmune $\geq 2.0$ ) with successive dilution of the serum of each sample.

\section{T cell proliferation}

On day 7 after the final immunization, spleens were collected from immunized mice. A suspension of single splenocytes was made and $1 \times 10^{5}$ cells/well were inoculated onto a 96-well plate in RPMI-1640 medium with $10 \%$ fetal bovine serum and stimulated in vitro by each of the following antigens: $20 \mu \mathrm{g} / \mathrm{mL}$ ConA as a positive control, $10 \mu \mathrm{g} / \mathrm{mL}$ LZP3 protein as a specific antigen, $2.0 \mu \mathrm{g} / \mathrm{mL}$ BSA as an irrelevant antigen, or medium. The plate was incubated with $5 \% \mathrm{CO}_{2}$ for $48 \mathrm{~h}$ at $37^{\circ} \mathrm{C}$.

To determine lymphocyte proliferation, $20 \mu \mathrm{L}$ MTT solution [3-(4,5-dimethylthiazol-2-yl)-2,5-diphenyltetrazolium bromide, $5 \mathrm{mg} / \mathrm{mL}$ in $\mathrm{PBS}, \mathrm{pH} 7.2-7.4]$ was added to each well and further incubated for $4 \mathrm{~h}$ at $37^{\circ} \mathrm{C}$. One hundred microliters of DMSO was added to each well, and the absorbance was measured at $570 \mathrm{~nm}$ using a microplate spectrophotometer (Benchmark Plus ${ }^{\mathrm{TM}}$, BioRad). Data are reported as stimulation index, calculated as the mean absorbance of triplicate wells stimulated with an antigen, and divided by the mean absorbance of triplicate wells stimulated with the medium ( $A_{\text {antigen }}$ )

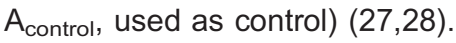

\section{Detection of contraceptive efficacy}

Immunized ICR female mice were mated on day 7 after the last immunization with healthy fertile male ICR mice. Mating was performed by housing two immunized female mice together with a male mouse in one cage. The 


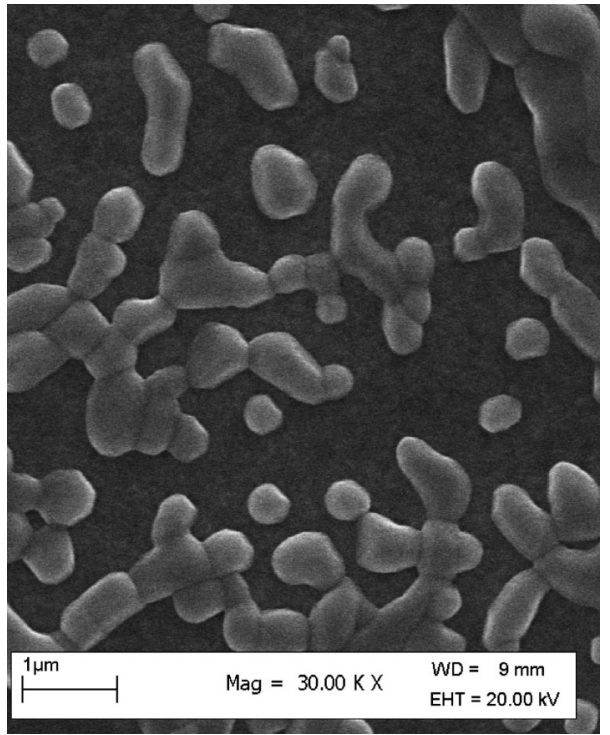

Figure 1. Scanning electron microscope (SEM) analysis of the chitosan-encapsulated plasmid DNA. DNA plasmids were encapsulated by the chitosan at the ratio of $1: 7$, and the generated chitosan-DNA complexes were observed under the SEM at a magnification of $30,000 \times$.

male and female mice were co-habited for 16 days to assess the efficacy of the contraceptive.

\section{Histological analysis of the ovaries}

Mouse ovaries were fixed in $4 \%$ paraformaldehyde buffer, dehydrated and embedded in paraffin, and subsequently sectioned at a thickness of $5 \mu \mathrm{m}$. The slides were stained with hematoxylin and eosin (HE), and then observed and photographed using a Leica inverted fluorescence microscope (Leica, DMI Series, Germany).

\section{Statistical analysis}

Data are reported as means \pm SE, and were analyzed using the one-sided Student $t$-test and one-way analysis of variance with the GraphPad Prism 4 software. A value of $\mathrm{P}<0.05$ was considered to be statistically significant.

\section{Results}

\section{Characterization of chitosan-DNA nanoparticles}

The morphology of the chitosan-DNA nanoparticles was observed with scanning electron microscopy (Figure 1). The size of chitosan-DNA nanoparticles was approximately 100-1000 nm. The protective effect of nanoparticles was detected using DNase I digestion. The nanoparticles completely protected DNA plasmids from digestion by DNase I, whereas the naked DNA was completely degraded by DNase I after $30 \mathrm{~min}$ (Figure 2). These results show that chitosan could protect DNA vaccine from degradation

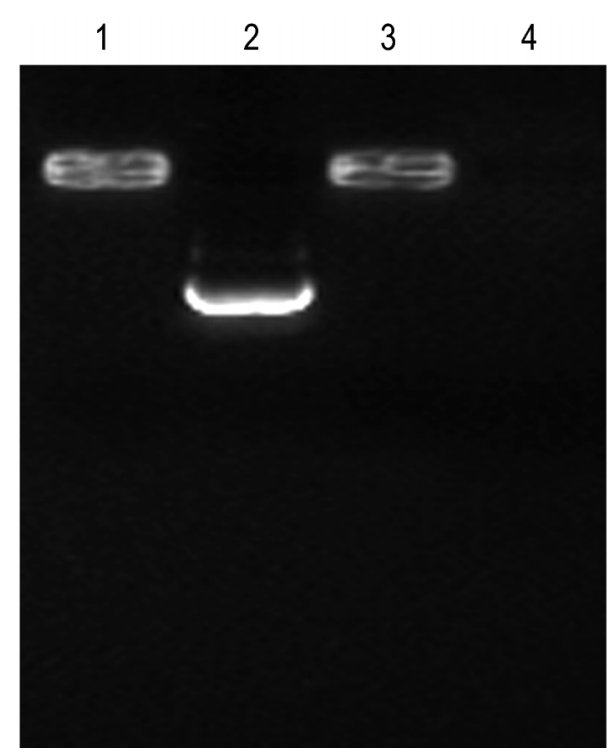

Figure 2. Degradation of the chitosan-DNA nanoparticles by DNase I. The chitosan-DNA nanoparticles and naked DNA plasmids were all digested with or without DNase I (RNase free, $40 \mathrm{U} / \mu \mathrm{L}$ ) at $37^{\circ} \mathrm{C}$ for $30 \mathrm{~min}$. The resulting products were analyzed by agarose gel electrophoresis. Lane 1 , chitosan-DNA nanoparticles were digested without DNase I; lane 2, naked DNA plasmids were digested without DNase I; lane 3, chitosan-DNA nanoparticles were digested by DNase I; lane 4, naked DNA plasmids were digested by DNase I.

\section{Transcription expression of mIL-33 plasmid in mouse hepatocytes}

In order to confirm the expression of mIL-33 plasmids in the eukaryotic cells, plasmid pcDNA3-mIL-33 was transfected into mouse hepatocytes. Total RNA was isolated $8 \mathrm{~h}$ after transfection and RT-PCR was conducted. A specific band of $801 \mathrm{bp}$ was observed from the cells transfected with pcD-m/L-33, which is consistent with the size of $\mathrm{mlL}-33$, whereas a similar size band was not displayed in the negative control groups (Figure 3). The results revealed that the construct encoding $\mathrm{m} / \mathrm{L}-33$ was expressed in eukaryotic cells.

Systemic IgG Ab responses to different nanoparticles

To investigate whether these different nanoparticles could induce humoral immune responses, serum samples were collected on days $14,28,42,56$, and 70 after the first immunization, and anti-LZP3 lgG Abs were detected by ELISA. As shown in Figure 4A, the group immunized with chi-pcD-Lzp3 produced LZP3-specific IgG Abs, which were significantly higher than control groups immunized with chitosan, chi-pcDNA3, and chi-pcD-mIL33 on days 42 and $56(P<0.05)$. The level of LZP3specific IgG Abs produced by the mice co-immunized with chi-(pcD-Lzp3 + pcD-mIL-33) was statistically higher than that observed in the mice immunized with chi-pcD-Lzp3 


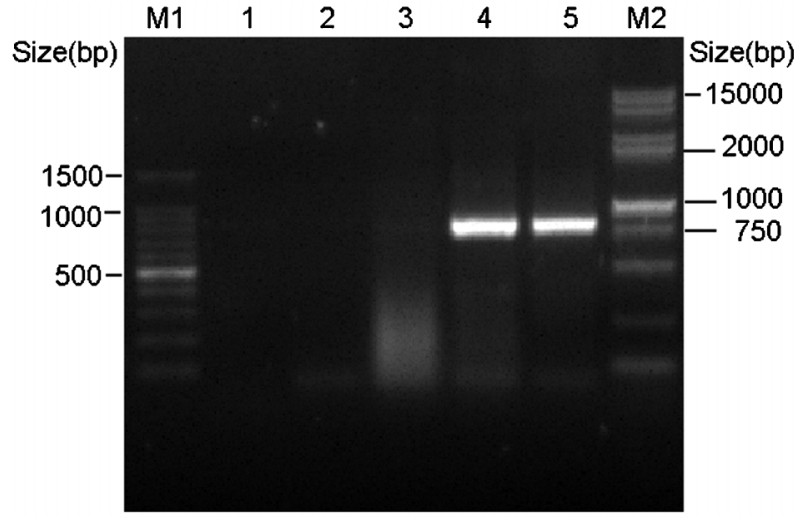

Figure 3. Expression of pcDNA3-mIL-33 in mouse hepatocytes. Total RNA was extracted from mouse hepatocytes $8 \mathrm{~h}$ after transfection with pcDNA3-mIL-33 using the hydrodynamicsbased transfection method. The templates used for RT-PCR were as follows: lane 1, distilled water as a negative control; lane 2, cDNA from hepatocytes of mouse transfected with pcDNA3 as a negative control; lane 3, RNA from hepatocytes of mouse transfected with pcDNA3-mIL-33 as a negative control; lane 4, cDNA from hepatocytes of mouse transfected with pcDNA3- $m / L-$ 33; lane 5, pcDNA3-mIL-33 plasmid served as a positive template. M1: 1500 bp DNA marker; M2: DL15,000+2000 bp DNA marker.

and in the control groups on days $28,42,56(\mathrm{P}<0.01)$ and $70(\mathrm{P}<0.05$ vs control groups; Figure 4A). LZP3-specific $\lg$ Abs were detected as early as 28 days in chi-(pcDLzp3 + pcD-mIL-33) co-immunized mice, suggesting that chi-(pcD-Lzp3+pcD-mIL-33) co-immunization not only enhanced the level of $\lg G \mathrm{Ab}$ but also quickly induced $A b$ production. The level of Abs reached the maximum on day 42. The highest IgG titer of the group co-immunized with chi-(pcD-Lzp3+pcD-m/L-33) was 4000 on day 42 $(\mathrm{P}<0.01$ vs chi-pcD-Lzp3 and control groups; $\mathrm{P}<0.05$ vs control groups; Figure 4B). Importantly, we analyzed the level of IgG $A b$ in infertile and fertile mice after mating. The levels of IgG Abs in infertile mice were significantly higher than those in fertile mice in the co-immunized group $(P<0.01$; Figure 5 ), suggesting that infertility was correlated with the higher level of Abs. The results showed that $m / L-33$ as a molecular adjuvant for pcDLzp3 DNA vaccine could enhance systemic Ab responses against ZP3 through mucosal immunization.

\section{Mucosal IgA responses}

After testing the systemic IgG $A b$ responses, we detected a mucosal response, antigen-specific slgA, in the vaginal washes and fecal extracts by ELISA. Chi(pcD-Lzp3+pcD-mIL-33) co-immunization quickly induced high levels of LZP3-specific slgA in the vaginal washes and reached peak responses on day 28 after the first immunization. The slgA levels in response to coimmunization were statistically higher than those in mice immunized with chi-pcD-Lzp3 and the control groups on days 28,42 , and 70 . On day 56, both chi-(pcDLzp3 + pcD-mIL-33) and chi-pcD-Lzp3 induced higher slgA levels than control groups, but the slgA level of chi-pcD-Lzp3 quickly decreased on day 70 (Figure 6A). Both chi-(pcD-Lzp3+pcD-m/L-33) and chi-pcD-Lzp3 induced LZP3-specific sIgA in fecal extracts on day 28 , and the level of slgA induced by chi-(pcD-Lzp3+pcD$m / L-33)$ was significantly higher than that induced by chipcD-Lzp3 and the control groups $(\mathrm{P}<0.05$ vs chi-pcDLzp3 and control groups; Figure 6B). LZP3-specific slgA in mice immunized with chi-pcD-Lzp3 decreased to basal levels on day 42, but a high level of LZP3-specific slgA in mice co-immunized with chi-(pcD-Lzp3+pcD-m/L-33) remained on day 42 . These results suggest that $\mathrm{mIL}-33$ not only increases the level of slgA induced by LZP3 DNA vaccine but also enhances the longevity of slgA.

\section{T cell proliferation in vitro}

The above results show that mIL-33 enhanced systemic and mucosal Ab responses induced by LZP3 DNA vaccine. We next examined whether mIL-33 enhanced cellular responses. T cell proliferation in vitro was assessed by the MTT method. The level of T cell proliferation induced by chi-(pcD-Lzp3+pcD- $m / L-33)$ was significantly higher than that of other groups $(P<0.05$; Figure 7). The level of $\mathrm{T}$ cell proliferation induced by chipcD-Lzp3 was somewhat higher than that of the control groups but was not significantly different. The results indicated that IL-33 as a mucosal adjuvant also enhanced antigen-specific cellular immune responses.

\section{Analysis of antifertility}

To detect the antifertility effect of the mice immunized with different nanoparticles, the rate of fertility was recorded. The results showed that mice of the coimmunized group had the lowest birth rate and mean litter size compared with the other groups. Three of 8 female mice in the co-immunized group were infertile, the other 5 females had 54 pups in total, and the average litter size for the entire group was 6.75 pups, that is, significantly lower than that of other groups (Table 1). Only one mouse in the group immunized with chi-pcD-Lzp3 was infertile, and the average litter size was 9.25. All females in other control groups were fertile. These results showed that the fertility of mice co-immunized with chi-(pcD-Lzp3+pcD-mIL-33) by intranasal delivery was reduced.

\section{Ovarian pathology}

Ovaries were collected from immunized mice 6 weeks after mating. Ovarian slides were prepared and stained with $\mathrm{HE}$. The results indicated that the fertile mice immunized with chi-(pcD-Lzp3 + pcD-m/L-33) or chi-pcDLzp3 or other control groups had normal follicles in numbers and in morphology with primordial, primary, secondary, tertiary, and mature follicles (Figure 8A-F). The mature follicles contained oocytes surrounded by a single 

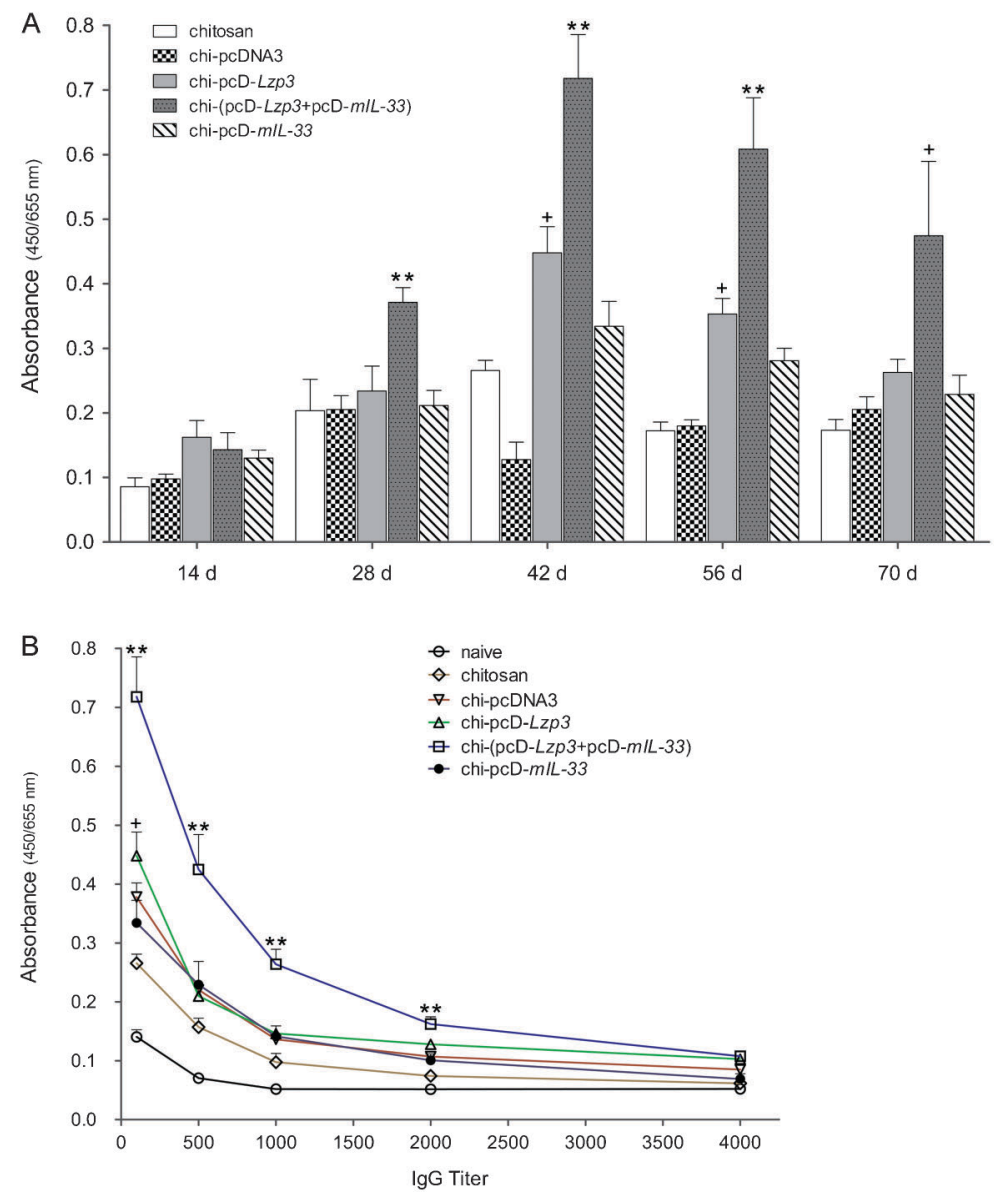

layer of granulosa cells. However, the infertile mice coimmunized with chi-(pcD-Lzp3 + pcD-mIL-33) showed aberrant development of ovarian follicles (Figure 8E1), where secondary follicles and tertiary follicles were absent and the number of primary follicles was reduced. The results suggest that $\mathrm{T}$ cell responses induced by chi-(pcD-Lzp3+pcD-mIL33) co-immunization may cause an abnormal morphological structure of the ovary that may be correlated with lower fertility.

\section{Discussion}

In order to enhance the immunogenicity of DNA vaccines, many materials, such as liposomes and poly(DL-lactide-co-glycolic acid) microspheres, have been tested for protecting the DNA from degradation $(30,31)$. In the present study, the chitosan-DNA nanoparticles displayed resistance against DNase I degradation (Figure 2). This could result in that a greater amount of plasmid DNA in the chitosan-DNA complex was not degraded, more DNA would be used for transcription, leading to the formation of a greater amount of antigenic protein and the generation of a better immune response (32). Chitosan
Figure 4. Serum anti-LZP3 IgG of ICR mice immunized intranasally with different chitosanDNA nanoparticles. Serum samples were collected from mice ( $n=12 /$ group) immunized with different nanoparticles on days (d) $14,28,42,56$, and 70 after the 1 st immunization. A, Anti-LZP3 IgG levels of serum (diluted at 1:100) were detected by ELISA on days 14, 28, 42, 56, and 70. ${ }^{+} \mathrm{P}<0.05$, compared to the control groups immunized with chitosan, chi-pcDNA3 and chipcD-mIL-33; ${ }^{* *} \mathrm{P}<0.01$, chi-(pcD-Lzp3 + pcD$m / L-33)$ group compared to the chi-pcD-Lzp3 group and the control groups (one-way ANOVA). $B$, Serum anti-LZP3 IgG levels (diluted from $1: 100$ to $1: 4000$ ) were assessed by ELISA on day 42 after the 1 st immunization. ${ }^{+} \mathrm{P}<0.05$, chipcD-Lzp3 group compared to the control groups; ${ }^{* *} \mathrm{P}<0.01$, chi-(pcD-Lzp3+pcD-mIL-33) group compared to the chi-pcD-Lzp3 group and the control groups (one-way ANOVA).

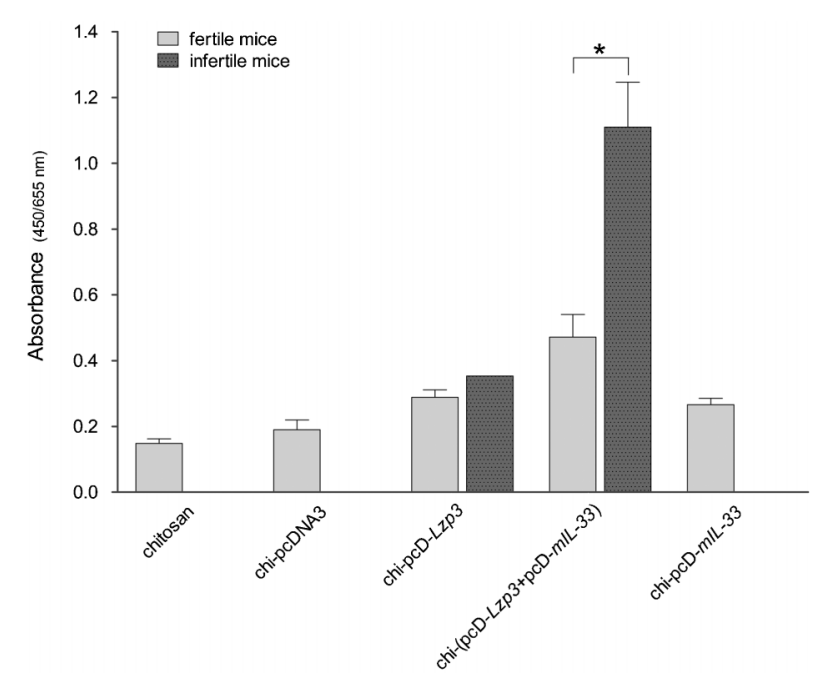

Figure 5. Anti-LZP3 lgG levels in serum of fertile and infertile mice. Anti-LZP3 IgG levels in serum of fertile and infertile mice $(n=8 /$ group) were detected by ELISA on day 56 after the 1 st immunization. ${ }^{*} P<0.01$, lgG levels in infertile mice co-immunized with chi-(pcD-Lzp3 + pcD-mIL-33) compared to fertile mice (onesided Student $t$-test). 

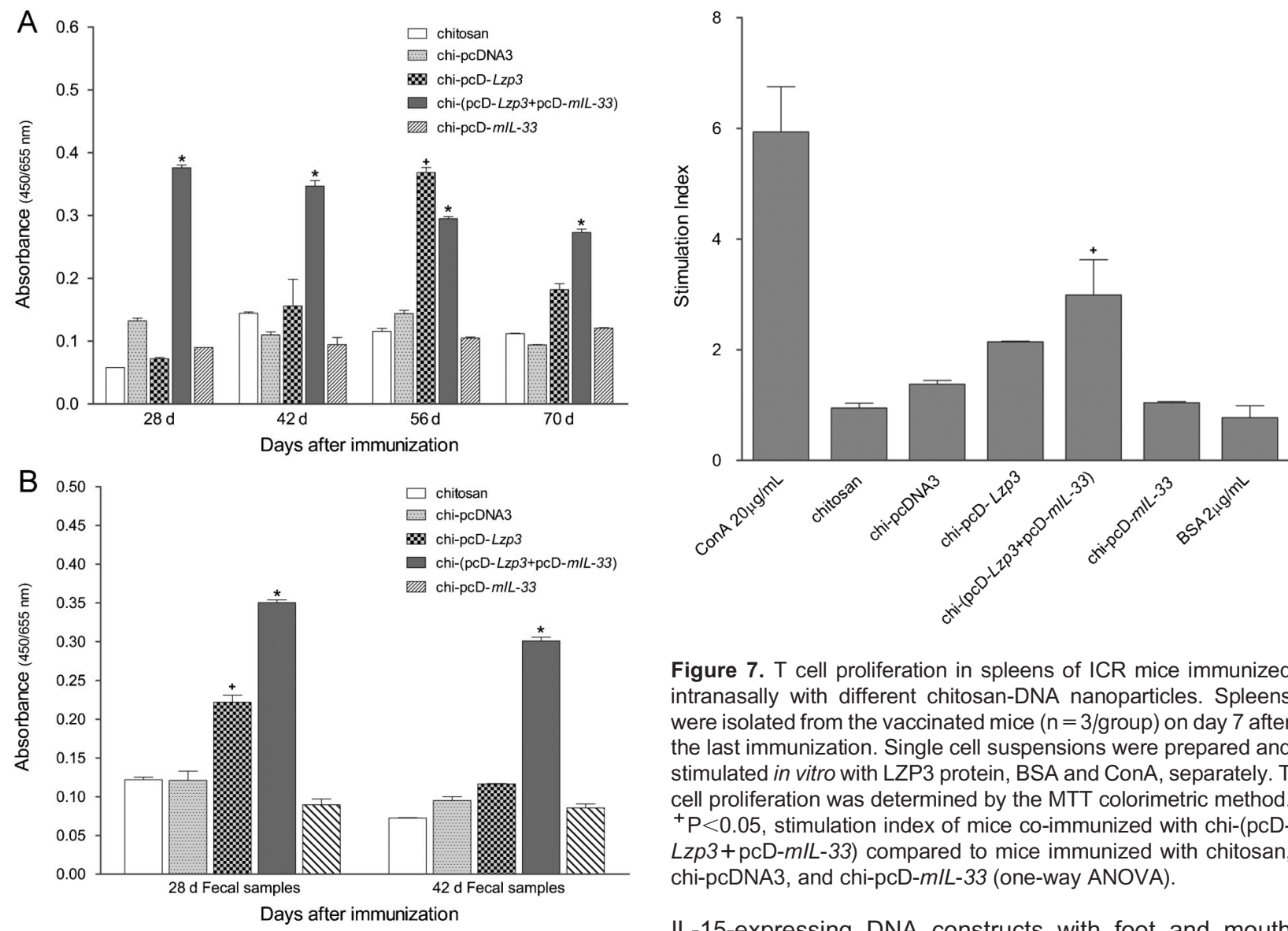

Figure 6. SIgA levels from vaginal washes and fecal samples of ICR mice immunized intranasally with different chitosan-DNA nanoparticles. Vaginal washes were collected from each immunized mouse ( $n=12 /$ group). Fecal samples were collected from immunized mice ( $n=12 /$ group). LZP3-specific slgA (secretory $\lg A$ ) antibodies in vaginal washes (diluted at 1:4) on days (d) 28 , 42,56 , and $70(A)$ and fecal samples on days 28 and $42(B)$ after the 1 st immunization were determined by ELISA. ${ }^{+} \mathrm{P}<0.05$, $\lg A$ levels in mice immunized with chi-pcD-Lzp3 compared to control group mice immunized with chitosan, chi-pcDNA3 and chi-pcD$m / L-33$ (one-way ANOVA). ${ }^{*} \mathrm{P}<0.05$, IgA levels in mice coimmunized with chi-(pcD-Lzp3+pcD-mIL-33) compared to mice immunized with chi-pcD-Lzp3 and the control groups (one-way ANOVA).

also has an immune-stimulating activity, including recruitment and activation of macrophages and polymorphonuclear cells, and enhancing the cytotoxic T cell response (33). Chitosan-DNA nanoparticles can induce mucosal immunity and produce slgA (33-35).

Cytokines have been used as mucosal adjuvants to overcome the mucosal tolerance and promote $\lg A$ secretion because of their pleiotropic functions (36). Cytokines can enhance both mucosal and systemic immunities. Intranasal co-immunization of mice with

Figure 7. T cell proliferation in spleens of ICR mice immunized intranasally with different chitosan-DNA nanoparticles. Spleens were isolated from the vaccinated mice ( $n=3 /$ group) on day 7 after the last immunization. Single cell suspensions were prepared and stimulated in vitro with LZP3 protein, BSA and ConA, separately. T cell proliferation was determined by the MTT colorimetric method. ${ }^{+} \mathrm{P}<0.05$, stimulation index of mice co-immunized with chi-(pcDLzp3 + pcD-mIL-33) compared to mice immunized with chitosan, chi-pcDNA3, and chi-pcD-mIL-33 (one-way ANOVA).

IL-15-expressing DNA constructs with foot and mouth disease virus DNA vaccine increased the levels of both $\lg G$ and $\operatorname{sig} A$ (36). IL-33 administration could induce production of $\lg A$ and $\lg G$ by increasing the production of Th2-associated cytokines, IL-5 and IL-13 (22), or activation of mast cells (37). Consistent with that, we also observed that IL-33 enhanced not only the level of systemic IgG but also mucosal slgA in the vaginal tract and intestine (Figures 4A, 6A and B). Interestingly, nasal immunization at one local $\lg A$ inductive site always induced specific immunity responses at distant mucosal effector sites through the common mucosal immune system (33); therefore, nasal immunization could produce a strong genital-vaginal mucosal immune response and mucosal IgA antibody (38). Our study showed that coimmunization with chi-(pcD-Lzp3+pcD-mIL-33) in the nasal cavity could also elicit $\lg A$ responses in the genital tract and intestine through the common mucosal immune system. All this evidence has demonstrated that intranasal immunization is an effective method to generate specific mucosal immune responses in the female reproductive tract and that $\mathrm{IL}-33$ is a good molecular adjuvant for intranasal administration.

IgG Abs against ZP3 in the circulation are very important to infertility, because the Abs can infiltrate 
Table 1. Fertility of mice immunized intranasally with different chitosan-DNA vaccines.

\begin{tabular}{|c|c|c|c|c|c|c|}
\hline Groups & No. mice ${ }^{a}$ & No. fertile & $\begin{array}{c}\text { Birth rate } \\
(\%)\end{array}$ & Total pups & Mean litter size ${ }^{c}$ & $\mathrm{P}$ \\
\hline Chitosan & 8 & 8 & 100 & 87 & $10.88 \pm 0.990$ & \\
\hline chi-pcDNA3 & 8 & 8 & 100 & 88 & $11.00 \pm 1.052$ & \\
\hline chi-pcD-Lzp3 & 8 & 7 & 87.5 & 74 & $9.25 \pm 1.359$ & \\
\hline chi-(pcD-Lzp3+pcD-m/L-33) & 8 & 5 & 62.5 & 54 & $6.750 \pm 2.502$ & $\begin{array}{l}0.0463^{d} \\
0.0437^{e}\end{array}$ \\
\hline chi-pcD-mIL-33 & 8 & 8 & 100 & 94 & $11.75 \pm 0.730$ & $0.0190^{f}$ \\
\hline
\end{tabular}

Data are reported as means \pm SE. ${ }^{a}$ Female ICR mice were immunized with chitosan or different chitosan-DNA vaccines at 2-week intervals. Mice were mated on day 7 after the final immunization. ${ }^{b}$ Birth rate was calculated by the fertile numbers divided by the number of total mated females in each group. ${ }^{C}$ Mean litter size was calculated by the total number of pups of each group divided by the number of total mated females in each group. ${ }^{d} \mathrm{P}<0.05$, chi-(pcD-Lzp3 $\left.+p c D-m / L-33\right)$ compared to chitosan. ${ }^{e} P<0.05$, chi-(pcDLzp3 + pcD-m/L-33) compared to chi-pcDNA3. ${ }^{\text {f }} \mathrm{P}<0.05$, chi-pcD-mIL-33 compared to chi-(pcD-Lzp3+pcD-m/L-33). The one-sided Student $t$-test was used for statistical analyses.

through ovarian follicles and bind to ZP to block spermoocyte binding in vivo (11). In several studies, high titers of ZP-specific total IgG Abs are associated with infertility in mice immunized with the recombinant ZP3 protein or ZP3 peptides $(12,18,39)$. Consistent with those studies, we also demonstrated that the higher level of total IgG Abs was correlated with infertility in mice in the group co-immunized with chi-(pcD-Lzp3+pcD-m/L-33) (Figure 5). Furthermore, chi-(pcD-Lzp3+pcD-mIL-33) co-immunization also induced high levels of mucosal sigA, which may be also correlated with decreased fertility. The mean litter size and birth rate of mice co-immunized with chi-(pcD-Lzp3+pcD-m/L-33) were significantly reduced compared with control groups.

Anti-LZP3-specific Abs may lead to abnormal development of ovaries. Calongos et al. (40) and Lloyd et al.
(16) found that anti-ZP Abs were detrimental to normal folliculogenesis and oocyte development. Anti-ZP Abs may give rise to follicle loss and premature ovarian failure because they impair zona pellucida formation in developing follicles and formation of gap junctions between the oocyte and granulosa cells $(16,40)$. Some reports suggested that anti-ZP Abs may induce infertility of immunized mice via two mechanisms, one disrupting ZP formation and oocyte development and the other blocking sperm-oocyte binding and oocyte fertilization. The degree to which these two mechanisms each bear responsibility for infertility may rely on the Ab titer and the interval since the beginning of the response (16). Our results showed that chi-(pcD-Lzp3+pcD-mIL-33) coimmunization induced significantly higher levels of Abs

\section{Fertile mice}
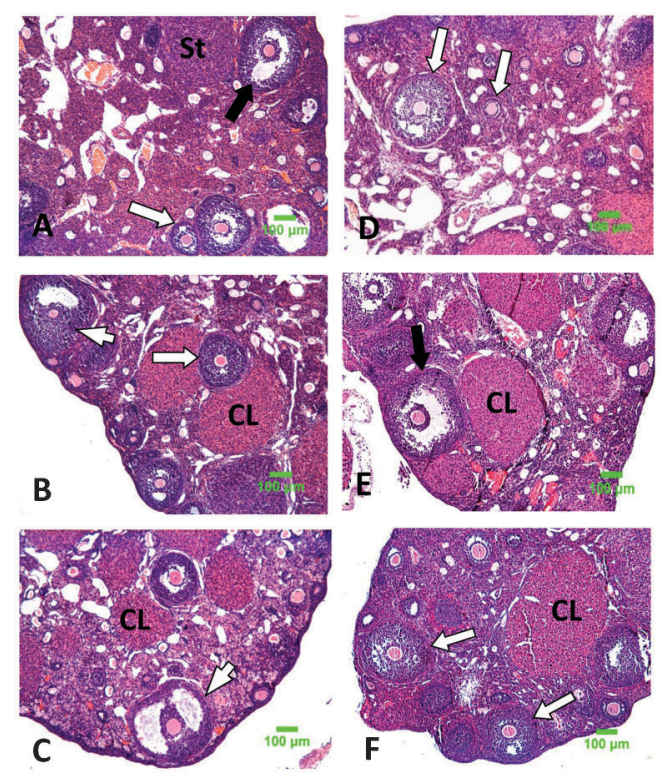

Figure 8. Histological examination of ovarian sections of the ICR mice immunized intranasally with different chitosan-DNA nanoparticles. Ovaries were collected from fertile and infertile mice $(n=6 /$ group $)$ on day 49 after final immunization. Ovarian sections were stained with hematoxylin and eosin and photographs (100X) were taken under a microscope. Ovaries were collected from naive mice $(A)$ or mice immunized with chitosan $(B)$, chi-pcDNA3 $(C)$, chi-pcD-Lzp3 $(D)$, chi-(pcD-Lzp3+pcD-mIL-33) (E, E1) and chi-pcD-mIL-33 $(F)$. Black arrows indicate normal mature ovarian follicles; white arrows indicate immature ovarian follicles; white arrowheads indicate tertiary follicles; black arrowheads indicate atrophic follicles; CL: corpora lutea; St: stroma. 
in infertile mice than in fertile mice, suggesting that the infertility may be due to the Abs blocking sperm-oocyte binding. We also observed abnormal development of follicles in infertile mice co-immunized with chi-(pcDLzp3+pcD-mIL-33), which may be correlated with the high level of $\mathrm{T}$ cell proliferation, and the abnormal development of follicles may also contribute to infertility.

Taken together, our results show that IL-33 is a good molecular adjuvant to enhance systemic and mucosal $\mathrm{Ab}$ responses and cellular responses induced by LZP3 DNA vaccine. Importantly, chi-(pcD- Lzp3+pcD-mIL-33) co-immunization significantly increased infertility. We

\section{References}

1. Cooper DW, Larsen E. Immunocontraception of mammalian wildlife: ecological and immunogenetic issues. Reproduction 2006; 132: 821-828, doi: 10.1530/REP-06-0037.

2. Lloyd ML, Shellam GR, Papadimitriou JM, Lawson MA. Immunocontraception is induced in BALB/c mice inoculated with murine cytomegalovirus expressing mouse zona pellucida 3. Biol Reprod 2003; 68: 2024-2032, doi: 10.1095/biolreprod.102.012880.

3. O'Rand MG, Widgren EE, Sivashanmugam P, Richardson RT, Hall SH, French FS, et al. Reversible immunocontraception in male monkeys immunized with eppin. Science 2004; 306: 1189-1190, doi: 10.1126/science.1099743.

4. Hardy CM, Hinds LA, Kerr PJ, Lloyd ML, Redwood AJ, Shellam GR, et al. Biological control of vertebrate pests using virally vectored immunocontraception. J Reprod Immunol 2006; 71: 102-111, doi: 10.1016/j.jri.2006.04.006.

5. Kirkpatrick JF, Lyda RO, Frank KM. Contraceptive vaccines for wildlife: a review. Am J Reprod Immunol 2011; 66: 40-50, doi: 10.1111/j.1600-0897.2011.01003.x.

6. Lo SC, Zeenathul NA, Sheikh Omar AR, Mohd Azmi ML. Current ZP3-based immunocontraceptive vaccine for free ranging wild pest. Pertanika J Trop Agric Sci 2011; 34: 1-16.

7. Naz RK, Gupta SK, Gupta JC, Vyas HK, Talwar AG. Recent advances in contraceptive vaccine development: a minireview. Hum Reprod 2005; 20: 3271-3283, doi: 10.1093/ humrep/dei256.

8. Srivastava N, Santhanam R, Sheela P, Mukund S, Thakral SS, Malik BS, et al. Evaluation of the immunocontraceptive potential of Escherichia coli-expressed recombinant dog ZP2 and ZP3 in a homologous animal model. Reproduction 2002; 123: 847-857, doi: 10.1530/rep.0.1230847.

9. Bagavant H, Fusi FM, Baisch J, Kurth B, David CS, Tung KS. Immunogenicity and contraceptive potential of a human zona pellucida 3 peptide vaccine. Biol Reprod 1997; 56: 764-770, doi: 10.1095/biolreprod56.3.764.

10. Xiang RL, Zhou F, Yang Y, Peng JP. Construction of the plasmid pCMV4-rZPC' DNA vaccine and analysis of its contraceptive potential. Biol Reprod 2003; 68: 1518-1524, doi: 10.1095/biolreprod.102.007849.

11. Zhang $X$, Lou $Y H$, Koopman M, Doggett $T$, Tung KS, Curtiss $\mathrm{R}$ III. Antibody responses and infertility in mice following oral immunization with attenuated Salmonella typhimurium expressing recombinant murine ZP3. Biol Reprod 1997; 56: 33-41, doi: 10.1095/biolreprod56.1.33. provide a potential strategy to control the population of wild animal pests.

\section{Acknowledgments}

We would like to thank Dr. Ji Ma, Dr. Jinyao Li and Ms. Jiayinaguli Zhumabai for the critical reading and for revising the manuscript. We also thank Mr. Yonghai Liang for his technical support. Research supported by the Research Starting Foundation for Doctors of Xinjiang University (\#BS120112) to Dr. Y.X. Tu, and the Natural Science Foundation of China (\#30760136) to F.C. Zhang.

12. Clydesdale G, Pekin J, Beaton S, Jackson RJ, Vignarajan $\mathrm{S}$, Hardy CM. Contraception in mice immunized with recombinant zona pellucida subunit 3 proteins correlates with Th2 responses and the levels of interleukin 4 expressed by CD4 + cells. Reproduction 2004; 128: 737745, doi: 10.1530/rep.1.00310.

13. Hardy CM, Beaton S, Hinds LA. Immunocontraception in mice using repeated, multi-antigen peptides: immunization with purified recombinant antigens. Mol Reprod Dev 2008; 75: 126-135, doi: 10.1002/mrd.20745

14. Ma X, Li J, Zhang F. Intranasal co-delivery with the mouse zona pellucida 3 and GM-CSF expressing constructs enhances humoral immune responses and contraception in mice. Scand J Immunol 2012; 76: 521-527, doi: 10.1111/ j.1365-3083.2012.02765.x.

15. Li J, Jin H, Zhang F, Du X, Zhao G, Yu Y, et al. Treatment of autoimmune ovarian disease by co-administration with mouse zona pellucida protein 3 and DNA vaccine through induction of adaptive regulatory T cells. J Gene Med 2008; 10: 810-820, doi: 10.1002/jgm.1200.

16. Lloyd ML, Papadimitriou JM, O'Leary S, Robertson SA, Shellam GR. Immunoglobulin to zona pellucida 3 mediates ovarian damage and infertility after contraceptive vaccination in mice. J Autoimmun 2010; 35: 77-85, doi: 10.1016/ j.jaut.2010.03.002

17. Choudhury S, Kakkar V, Suman P, Chakrabarti K, Vrati S, Gupta SK. Immunogenicity of zona pellucida glycoprotein-3 and spermatozoa YLP(12) peptides presented on Johnson grass mosaic virus-like particles. Vaccine 2009; 27: 29482953, doi: 10.1016/j.vaccine.2009.03.002.

18. Li J, Jin H, Zhang A, Li Y, Wang B, Zhang F. Enhanced contraceptive response by co-immunization of DNA and protein vaccines encoding the mouse zona pellucida 3 with minimal oophoritis in mouse ovary. J Gene Med 2007; 9: 1095-1103, doi: 10.1002/jgm.1069.

19. Cayrol C, Girard JP. The IL-1-like cytokine IL-33 is inactivated after maturation by caspase-1. Proc Natl Acad Sci U S A 2009; 106: 9021-9026, doi: 10.1073/ pnas.0812690106.

20. Yasuoka S, Kawanokuchi J, Parajuli B, Jin S, Doi Y, Noda $\mathrm{M}$, et al. Production and functions of IL-33 in the central nervous system. Brain Res 2011; 1385: 8-17, doi: 10.1016/ j.brainres.2011.02.045.

21. Miller AM, Xu D, Asquith DL, Denby L, Li Y, Sattar N, et al. 
IL-33 reduces the development of atherosclerosis. J Exp Med 2008; 205: 339-346, doi: 10.1084/jem.20071868.

22. Schmitz J, Owyang A, Oldham E, Song Y, Murphy E, McClanahan TK, et al. IL-33, an interleukin-1-like cytokine that signals via the IL-1 receptor-related protein ST2 and induces $\mathrm{T}$ helper type 2-associated cytokines. Immunity 2005; 23: 479-490, doi: 10.1016/j.immuni.2005.09.015.

23. Rank MA, Kobayashi $T$, Kozaki H, Bartemes KR, Squillace $\mathrm{DL}$, Kita H. IL-33-activated dendritic cells induce an atypical TH2-type response. J Allergy Clin Immunol 2009; 123: 1047-1054, doi: 10.1016/j.jaci.2009.02.026.

24. Bergmann C, Van Hemmen JL, Segel LA. Th1 or Th2: how an appropriate $\mathrm{T}$ helper response can be made. Bull Math Biol 2001; 63: 405-430, doi: 10.1006/bulm.2000.0215.

25. Van Roosmalen ML, Kanninga R, El Khattabi M, Neef J, Audouy S, Bosma T, et al. Mucosal vaccine delivery of antigens tightly bound to an adjuvant particle made from food-grade bacteria. Methods 2006; 38: 144-149, doi: 10.1016/j.ymeth.2005.09.015.

26. Mackenzie SM, McLaughlin EA, Perkins HD, French N, Sutherland T, Jackson RJ, et al. Immunocontraceptive effects on female rabbits infected with recombinant myxoma virus expressing rabbit ZP2 or ZP3. Biol Reprod 2006; 74: 511-521, doi: 10.1095/biolreprod.105.046268.

27. Zhang A, Li J, Zhao G, Geng S, Zhuang S, Wang B, et al. Intranasal co-administration with the mouse zona pellucida 3 expressing construct and its coding protein induces contraception in mice. Vaccine 2011; 29: 6785-6792, doi: 10.1016/j.vaccine.2010.12.061.

28. Kadir Z, Ma X, Li J, Zhang F. Granulocyte-macrophage colony-stimulating factor enhances the humoral immune responses of mouse zona pellucida 3 vaccine strategy based on DNA and protein coadministration in BALB/c mice. Reprod Sci 2013; 20: 400-407, doi: 10.1177/19337191124 59236.

29. Wang G, Tschoi M, Spolski R, Lou Y, Ozaki K, Feng C, et al. In vivo antitumor activity of interleukin 21 mediated by natural killer cells. Cancer Res 2003; 63: 9016-9022.

30. Gürsel M, Tunca S, Özkan M, Özcengiz G, Alaeddinoglu G. Immunoadjuvant action of plasmid DNA in liposomes. Vaccine 1999; 17: 1376-1383, doi: 10.1016/S0264-410X(98)00383-1.

31. He XW, Wang F, Jiang L, Li J, Liu SK, Xiao ZY, et al.
Induction of mucosal and systemic immune response by single-dose oral immunization with biodegradable microparticles containing DNA encoding HBsAg. J Gen Virol 2005; 86: 601-610, doi: 10.1099/vir.0.80575-0.

32. Bivas-Benita $M$, van Meijgaarden $K E$, Franken $K L$, Junginger HE, Borchard G, Ottenhoff TH, et al. Pulmonary delivery of chitosan-DNA nanoparticles enhances the immunogenicity of a DNA vaccine encoding HLA-A*0201restricted T-cell epitopes of Mycobacterium tuberculosis. Vaccine 2004; 22: 1609-1615, doi: 10.1016/j.vaccine. 2003.09.044.

33. Xu W, Shen $Y$, Jiang Z, Wang $Y$, Chu $Y$, Xiong S. Intranasal delivery of chitosan-DNA vaccine generates mucosal SIgA and anti-CVB3 protection. Vaccine 2004; 22: 3603-3612, doi: 10.1016/j.vaccine.2004.03.033.

34. Xu J, Dai W, Wang Z, Chen B, Li Z, Fan X. Intranasal vaccination with chitosan-DNA nanoparticles expressing pneumococcal surface antigen a protects mice against nasopharyngeal colonization by Streptococcus pneumoniae. Clin Vaccine Immunol 2011; 18: 75-81, doi: 10.1128/CVI.00263-10.

35. Khatri K, Goyal AK, Gupta PN, Mishra N, Vyas SP. Plasmid DNA loaded chitosan nanoparticles for nasal mucosal immunization against hepatitis B. Int J Pharm 2008; 354: 235-241, doi: 10.1016/j.ijpharm.2007.11.027.

36. Wang X, Zhang X, Kang Y, Jin H, Du X, Zhao G, et al. Interleukin15 enhance DNA vaccine elicited mucosal and systemic immunity against foot and mouth disease virus. Vaccine 2008; 26: 5135-5144, doi: 10.1016/j.vaccine.2008.03.088.

37. Xu D, Jiang HR, Kewin P, Li Y, Mu R, Fraser AR, et al. IL-33 exacerbates antigen-induced arthritis by activating mast cells. Proc Natl Acad Sci U S A 2008; 105: 10913-10918, doi: 10.1073/pnas.0801898105.

38. Holmgren J, Czerkinsky C. Mucosal immunity and vaccines. Nat Med 2005; 11: S45-S53, doi: 10.1038/nm1213.

39. Hardy CM, ten Have JF, Mobbs KJ, Hinds LA. Assessment of the immunocontraceptive effect of a zona pellucida 3 peptide antigen in wild mice. Reprod Fertil Dev 2002; 14 : 151-155, doi: 10.1071/RD01112.

40. Calongos G, Hasegawa A, Komori S, Koyama K. Harmful effects of anti-zona pellucida antibodies in folliculogenesis, oogenesis, and fertilization. J Reprod Immunol 2009; 79: 148-155, doi: 10.1016/j.jri.2008.06.003. 